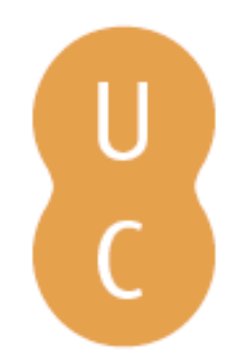

\title{
pompalina
}

\section{Razão filosófica e razão educativa: Filosofia da educação como Filosofia aplicada}

Autor(es): $\quad$ Pedro, Ana

Publicado por: Imprensa da Universidade de Coimbra

URL

persistente: URI:http://hdl.handle.net/10316.2/38385

DOI: $\quad$ DOI:http://dx.doi.org/10.14195/978-989-26-0486-2_7

Accessed : $\quad$ 26-Apr-2023 11:28:13

A navegação consulta e descarregamento dos títulos inseridos nas Bibliotecas Digitais UC Digitalis, UC Pombalina e UC Impactum, pressupõem a aceitação plena e sem reservas dos Termos e Condições de Uso destas Bibliotecas Digitais, disponíveis em https://digitalis.uc.pt/pt-pt/termos.

Conforme exposto nos referidos Termos e Condições de Uso, o descarregamento de títulos de acesso restrito requer uma licença válida de autorização devendo o utilizador aceder ao(s) documento(s) a partir de um endereço de IP da instituição detentora da supramencionada licença.

Ao utilizador é apenas permitido o descarregamento para uso pessoal, pelo que o emprego do(s) título(s) descarregado(s) para outro fim, designadamente comercial, carece de autorização do respetivo autor ou editor da obra.

Na medida em que todas as obras da UC Digitalis se encontram protegidas pelo Código do Direito de Autor e Direitos Conexos e demais legislação aplicável, toda a cópia, parcial ou total, deste documento, nos casos em que é legalmente admitida, deverá conter ou fazer-se acompanhar por este aviso.

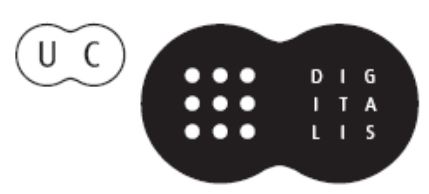


João Boavida

Ángel García del Dujo

Coordenação

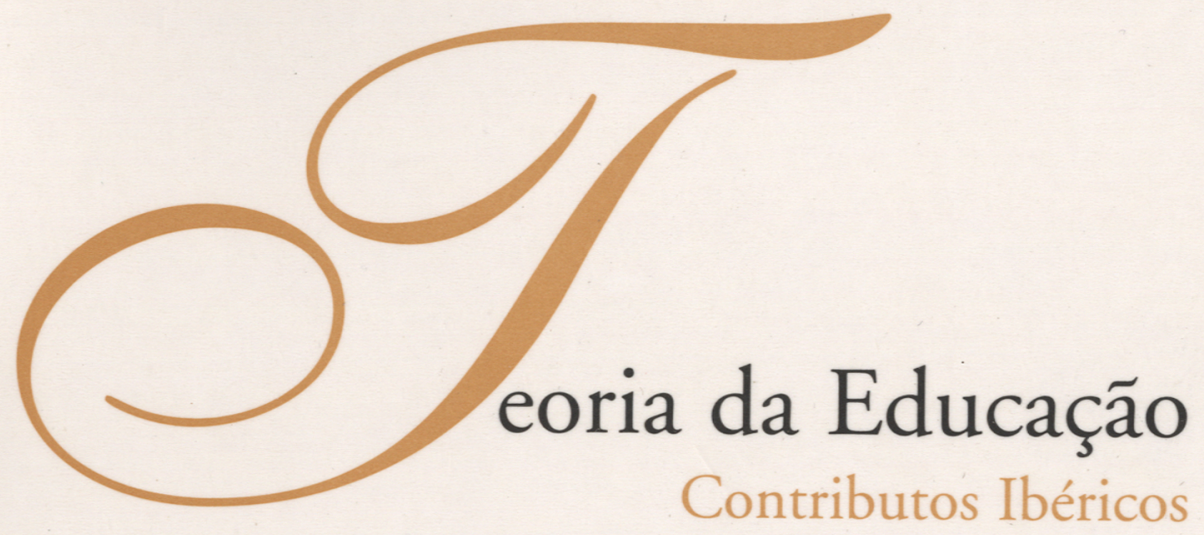


A na Pedro

Universidade de Aveiro

\author{
Razão Fil o sófica e Razão Educativa \\ - Fil osofia da Educação como Fil osofia Aplicada
}

A importância do levantamento de questões, tais como - para que se educa? —constitui, inevitavelmente, um campo de reflexão filosófica fundamental para quem actúa em educação, pois é através do exercício deste reflectir que se determinam modos distintos de poder, de decisão e de liberdade responsável de cada um.

Nesse sentido, e em nosso entender, a educação nunca poderá distanciar-se de um filosofar que se interroga permanentemente sobre o(s) sentido(s) do existir em articulação íntima com a vida e toda a aprendizagem experiencial que dela brota.

0 dearning by doing», de J. Dewey, é exemplo do que acabamos de referir acerca da importância da experiência na compreensão dos processos educativos que conduzem ao conhecimento e que se realizam ao longo de toda a vida.

Ao pensar a prática, a filosofia da educação tem, assim, por tarefa primordial analisar e ajudar a compreender as complexidades do mundo contemporâneo cruzando linguagens e perspectivando saberes que abram novos caminhos ao pensamento e a diversos modos de ser. 


\section{Retorno à filosofia da educação?}

A consciência da crise de valores da sociedade contemporânea leva-nos a assistir a um retorno do interesse pela Filosofia da Educação.

Com efeito, face a um vazio gerador de um mal-estar disseminado, esgotadas que estão as expectativas de uma resolução estritamente científica dos problemas pedagógicos (Bernardo, 2004, 81); face à instauração (quase) fatal de «/m tempo morto no desejo de saben (Lyotard, 1989, 50), sem a consequente recuperação do gosto inevitável pela aprendizagem, tende a recorrer-se a um sistema de princípios bem definidos e organizados, cuja principal função consiste em dar resposta ao problema instalado, como se de uma poção mágica se tratasse.

A ser assim, 0 alcance da intervenção da filosofia estaria confinado a determinados modelos de doutrinamento, em tudo contrário, como sabemos, à essência própria do filosofar que deve ter como fim último a liberdade de pensamento.

Ao olhar para 0 mundo em crise trata-se, então, para a Filosofia da Educação, de interrogar o(s) sentido(s) da(s) racionalidade(s) e de ter um olhar crítico e activo face aos problemas apresentados pela contemporaneidade e, acerca dos quais, é preciso agir e saber agir, pensar e saber pensar, interrogar e renovar o pensamento (Medeiros, 2002, 125).

Este é, por isso, um tempo propício à Filosofia da Educação, de inevitável problematização rigorosa, na dupla exigência de pensamento e de acção crítica. É, pois, num contexto de dinâmica reflexiva que o lugar que a Filosofia da Educação constitui um olhar crítico não só sobre as finalidades da educação, mas também sobre as metodologias utilizadas nos seus processos de investigação. 
É manifesta a estreita relação histórica entre Filosofia e Educação ao longo dos tempos; basta, para tal, recordarmos Sócrates, Platão, Aristóteles, Rousseau, Kant, Herbart(1) e Dewey, entre muitos outros, de que a História da Filosofia nos dá eco.

Na verdade, como refere Saez, $(1985,19)$ «la estrecha ligación de la tarea educativa com la filosofía no admite discusión...La relación es clara porque todo educador parte de una concepción del mundo y de la vida para alcanzar unas metas de perfeccionamiento».

Assim sendo, toda a educação é filosófica (Kneller, 1979), pois, ao ser analisada sob o prisma filosófico, o processo educativo encerra em si, desde logo, uma filosofia da educação, implícita ou explícita. Através da reflexão radical e totalizante capaz de articular todos os saberes atribuindo-lhes sentido(s), a filosofia tem por tarefa indicar à educação as opções fundamentais a fazer, bem como reflectir sobre a natureza dos seus fins.

(1) Segundo Cantillo $(1987,187)$ não deixa de ser significativo que a Pedagogia tenha surgido, enquanto ciência, a partir da obra fundamental de Herbart - Pedagogia Geral, fundamentando-a na filosofia prática e na psicologia.

Mas, apesar de a relação entre filosofia e pedagogia parecer evidente, não existe unanimidade relativamente à mesma. Vejamos: 1) a pedagogia identifica-se com a filosofia. Esta é a postura do idealismo para quem a pedagogia é filosofia. A razão evidente é que a filosofia é a ciência do espírito absoluto que se vai realizando na história e a pedagogia, a ciência da formação do espírito; $\log 0$, a filosofia coincide com a filosofia (Gentille); 2 ) A pedagogia é 0 culminar da filosofia. Este é o ponto de vista defendido pela corrente científica espiritual de Dilthey e Spranger, que entendem a filosofia como uma concepção histórica do universo que reflecte a situação do momento. 0 filósofo interpreta 0 espirito epocal e 0 pedagogo põe-no em prática. 0 fim da filosofia é 0 de dar lugar à pedagogia. 3) A pedagogia depende da filosofia. E a concepcão do idealismo neoKantiano defendida por Natorp e Cohn. A base da educação é a totalidade da filosofia por ser esta a que proporciona a ideia de cultura integral; desta forma, a filosofia é 0 suporte da pedagogia, constitui o ponto de partida e de chegada. 4) A pedagogia inspira-se na filosofia. Esta è a postura do pragmatismo do norte-americano Dewey. A filosofia proporciona ao educador hipóteses operantes e uma visão mais compreensiva dos problemas. 5) A pedagogia utiliza a filosofia. Esta tese é sustentada por Nassif: a pedagogia é um saber autónomo que se vale da filosofia como de outros saberes. 6) A pedagogia nada tem que ver com a filosofia. Esta tese é defendida pelos adeptos do cientifismo que valorizam as ciências empíricas. Para estes a pedagogia deve prescindir da filosofia, já que a ciência, por si só, é suficiente. 
Consequentemente, a filosofia da educação(2) mais não é do que uma tentativa de resposta às interrogações fundamentais da realidade educativa humana ou, se quisermos, uma crítica da razão educativa (Charbonnel, 1988).

Mas, reflectir sobre as questões educativas fundamentais —em que consiste ser livre? São os valores absolutos ou relativos? —não será, também, reflectir sobre as grandes problemáticas filosóficas do ser e das suas limitações enquanto paradoxos da sua finitude e do seu sentido? (Carvalho, 2001).

Deste modo, a filosofia da educação caracteriza-se pelo conjunto de reflexões que estabelece sobre as problemáticas educativas repercutindo nos processos educativos sentidos típicos da reflexão filosófica.

Por sua vez, a educação ao encetar um diálogo profundo com a filosofia propicia 0 aparecimento de atitudes de abertura e de radicalidade crítica de pensamento.

«Quando se clausura la pregunta filosófica por el aprender, cuando no se cuestiona lo que es propiamente saber ni se pregunta por el saber del saber, el aprendizaje deviene mero atenerse a un proceso bajo la presión dominante del resultado. Entonces, el aprender pierde su referencia básica a la idea de validez, constitutiva de todo saber. El aprendizaje ya no trata de la verdad del concocimiento ganado, sino que se subveierte en el puro almacenamiento de dados... La enseñanza renuncia al propósito de estimular la comprensión de lo aprendido; la transmissión de un saber mediatizado por la perspectiva de una eficácia cuantificable es empujada al camino del adoctrinamiento, es decir, el condicionamiento que margina la conciencia del educando en su competência crítica» (Heitger, 1993, 93).

Neste sentido, a relação da educação com as questões filosóficas não implica uma dependência face a um sistema de ideias previamente concebido por esta, pois, tal como refere Heitger (1993), consideramos que uma filosofia da

(2) Para Octavi Fullat, «no hay una filosofia de la educación sino múltiples, en insoslayables mudanzas todas ellas. Si la unidade puede hablarse se referirá siempre a los prolegómenos 0 condiciones a toda posible filosofia de la educación» $(1982: 1)$. 
educação é fruto do pensar e do reflectir crítico e interrogante, como temos vindo a afirmar, bem como do reconhecimento do pressuposto antropológico no qual radica a possibilidade e a necessidade da educação. A filosofia da educação é, assim, aquela que estuda o ser ou a natureza da educação.

Deriva daqui 0 facto de que, para a filosofia da educação, a educação é, antes de mais, uma questão de natureza antropológica, uma vez que se interroga sobre 0 carácter teleológico da educação e sobre a natureza de um homem que, para 0 ser, carece de educação. Significa, assim, que a filosofia se afirma na sua irredutível radicalidade crítica(3).

Pela crítica da razão educativa, a filosofia da educação, ou seja, a reflexão sobre 0 pensamento da educação não deixa de evidenciar, por uma replicação reflexiva, 0 aparecimento de antinomias, muito embora não lhe caiba superá-las.

A reflexão crítica da filosofia a que nos referimos radica, em última análise, no questionamento ontológico do homem face ao mundo e ao ser, 0 que lhe permite situar-se num contexto que ultrapasse qualquer determinismo finalístico.

Para além disso, 0 objecto fundamental da filosofia da educação não é a procura da realização imediata dos seus pressupostos de natureza eminentemente teórica, mas antes 0 diálogo fundamental em contexto pedagógico que se realiza a vários níveis, dos quais destacamos 0 nível ético, de que falaremos mais adiante.

Concluímos, assim, que «hay dos cuestiones básicas de la Pedagogia que solo pueden ser abordadas filosoficamente: la pregunta por el sentido y la finalidad, y la cuestión de la normatividad pedagógica, la que tematiza los princípios de la acción educativa» (Heitger, 1993, 95).

(3) para Kneller (1979), a fillosofia da educação é uma aplicação da filosofia geral ao campo da educação assumindo um carácter especulativo, prescritivo e crítico. Especulativa enquanto procura estabelecer teorias sobre a natureza do homem, a sociedade e 0 mundo, por meio dos quais serão ordenados e interpretados os dados da investigação educacional; prescritiva, quando define os fins a que a educação se deve subordinar; crítica, quando reflecte acerca da racionalidade e da coerência dos ideais educativos. 
3. A filosofia da educação enquanto filosofia aplicada

Muitos são os autores que procuram saber se a filosofia da educação é, ou não, uma filosofia aplicada. Esta é considerada, prioritariamente, uma filosofia aplicada quando retoma e reorienta os contributos dos outros saberes, com vista ao esclarecimento dos fins da educação, como é a posição defendida por Quintana Cabanas.

No seu entender, também se trata de uma filosofia especial ao dedicar a sua reflexão à natureza ôntica da educação, entendendo-a como um fenómeno real e autónomo.

Neste sentido, para Quintana Cabanas, a «filosofia da educação es la explicación filosófica de la educación, y la elaboración crítica de los princípios ideológicos que presupone el acto educativo y que sirven para oriéntalo» (1983, 110-111).

Também para Carvalho (2002), a filosofia da educação é uma filosofia aplicada quando está interessada não no conhecimento como um fim em si mesmo, mas 0 interpreta como um meio para resolver problemas práticos da vida quotidiana e utiliza os conhecimentos adquiridos para os aplicar aos problemas da existência humana.

Por sua vez, Campillo $(1974,38)$, define a filosofia da educação como «una disciplina formalmente filosófica y materialmente educativa 0 pedagógica. Pertenence a lo que se há venido llamando Filosofia derivada», cujos conteúdos seriam constituídos por questões ontológicas, epistemológicas e éticas.

Já para Nassif, a filosofia da educação é «el conjunto de reflexiones sobre el hecho y el proceso educativo conectado con la totalidad de la cultura y del hombre, al mismo tiempo que la conciencia de unidad y la dirección del obrar educativo» (Nassif: 1985, 13).

As diversas posturas sobre a(s) filosofia(s) da educação que apresentamos ajudam-nos a considerá-la quer enquanto filosofia aplicada quer enquanto disciplina autónoma; pensamos que esta é, essencialmente, uma filosofia 
aplicada, como é 0 caso da axiologia educativa, ao colocar o horizonte da reflexão filosófica ao serviço da educação.

No que diz respeito ao seu âmbito, reconhecemos que a filosofia da educação tem por preocupação quer uma ontologia ou fenomenología da educação; quer uma análise da linguagem educativa com preocupações sobre a sua clarificação; quer uma epistemología pedagógica (reflexão radical sobre os pressupostos da educação, estrutura e sistema da pedagogia); quer ainda uma teleología educativa e uma axiologia pedagógica que se ocupa dos ideais, fins e valores da educação.

\section{A natureza pragmática da filosofia da educação}

É comum ouvirmos falar da filosofia como um saber eminentemente teórico e abstracto em que, tal como refere Abbagnano, $(1976,7)$ «perdura 0 preconceito de que a filosofia se afadiga com problemas que não têm a mínima relação com a existência humana e continua encerrada em uma esfera longínqua e inacessível aonde não chegam as aspirações e necessidades dos homens» E, mais adiante, acrescenta: «É que 0 valor de uma filosofia não se mede pelo quantum de verdade objectiva que ela contém, mas tão só pela sua capacidade de servir de ponto de referência a toda a tentativa de compreender-se a si e ao mundo» Qdem, 12).

Ora, é precisamente neste sentido que a dimensão pragmática da educação foi sublinhada por alguns pensadores, nomeadamente, J. Dewey através da sua filosofia da educação. Para este autor, a concepção filosófica da educação tem consequências práticas no conhecimento. Com efeito, este possui um valor instrumental, pois mede-se pela sua utilidade. Embora este conceito seja discutível, consideramos que 0 mérito do autor está no facto de defender a importância do conhecimento para e através da acção (Medeiros, 2002). 
Na verdade, a exigência de urna educação activa, em que a aprendizagem so pode resultar de uma actividade de cariz investigativo e experiencial por parte do aprendiz, traduzida no lema *Learning by doing», assume uma importância central em toda a sua filosofia da educação, ao estabelecer que a aprendizagem, ou seja, a educação, é concebida em termos de experiência. Este facto constitui uma tarefa para desenvolver e aperfeiçoar ao longo da vida, pelo que a educação se baseia na vida experiencial.

É, portanto, a actividade do sujeito que é colocada no centro de todo 0 processo de conhecimento do sujeito partindo sempre dos seus interesses postos em acção. Ou seja, é na relação entre a experiência e 0 fazer que surge 0 verdadeiro conhecimento; este alimenta-se da vida valorizando uma educação aberta a todos os domínios da experiência humana. Todavia, apesar de Dewey defender que toda a educação vem da experiência, tal não significa que todas as experiências sejam genuinamente educativas.

A importância central atribuída à experiência e à acção revela-se, como podemos verificar, uma peça essencial na obtenção de conhecimento em que a valorização da experiência constitui um estímulo para 0 pensar livre e autónomo.

\section{Desafios à Filosofia da Educação}

Para Medeiros $(2002,126)$, um dos primeiros desafios que se coloca à filosofia da educação consiste no facto de esta poder desenvolver linhas de investigação que lhe permita estar presente nos debates educativos: «torna-se simultaneamente necessário desenvolver um discurso e uma praxis de Filosofia da Educação que permita recuperar e expandir, de modo fundamentado, uma visão interdisciplinar...dos saberes educativos». É importante avançar para novas reconfigurações da Filosofia da Educação. 
Nesse sentido, o diálogo da Filosofia da Educação com outras disciplinas e áreas científicas afigura-se-nos crucial, no sentido de possibilitar a construção de um saber articulado das perspectivas teóricas e práticas, bem como a obtenção de uma melhor compreensão dessa natureza interactiva.

Para tal, trata-se de problematizar a natureza dos saberes que a sua reflexão tenta organizar, procurando uma resposta através dos contributos de outras reflexões vindas quer da Antropologia, quer da Ética ou da Axiologia, da Biologia, da Psicologia, Sociologia, por exemplo.

Ao fazê-lo, a filosofia da educação cumpre funções de fundamentaçãa da acção educativa, de orientação teleológica, de conhecimento teórico, interpretativo e justificativo que relacione dados, conhecimentos e teorias (Ibidem).

A acrescer a estes desafios à filosofia da educação, Paulo Freire refere aquela que consideramos a mais importante de todas as que já enunciamos e que se prende com a sua verdadeira natureza crítica, e, portanto, interventora, na educação e na realidade.

Não deixa de ser interessante notar, contudo, que, à semelhança de Dewey, esta intervenção é relativa ao domínio da prática e do fazer, do movimento consciente, baseada no exercício da prática humana reflexiva e ética.

É neste sentido que, também em Paulo Freire, vemos que a educação assume uma função essencial no desenvolvimento de uma atitude de cidadania participativa, com vista à necessária formação integral de cada um. Desta, deve fazer parte a imprescindível atitude crítica face à vida e à existência humana que a filosofia da educação tem por função ajudar a estabelecer com base numa atitude racional crítica. A educação deve ser, portanto, no entender do autor, verdadeiramente problematizadora a fim de permitir 0 desenvolvimento da consciência crítica. 


\section{Filosofia da educação e contemporaneidade do discurso pe- dagógico: a ética e a interculturalidade aplicadas à educação}

Parece ser uma realidade incontornável a presença dos valores nos discursos e nas práticas educativas retomadas na actualidade. Com efeito, os valores jamais deixaram de constituir motivo de reflexão do domínio da educação pela simples razão de que «não há educação sem valores» (Reboul, 1989; Pedro, 2002).

No entanto, apesar da reflexão sobre a axiologia educativa ser uma constante em todas as expressões do pensamento filosófico-pedagógico, aquela tem vindo a assumir quer uma certa forma de nihilismo moral, ao nível dos pressupostos dos actos educativos e que se traduz por uma neutralidade axiológica global; quer um certo grau de relativismo moral, afirmando a relatividade dos valores em função do contexto histórico a que se referem; quer ainda, uma certa (in)tolerância face ao outro, enquanto diferente.

Daí a importância que tem vindo a adquirir, últimamente, 0 conceito alteridade no contexto do discurso pedagógico, o qual subjaz à problemática essencial da pessoa. Desta reflexão emerge uma ética da responsabilidade que, no entender de Carvalho $(2001,117)$ é fundamento e finalidade da educação: «Fundamento porque, sendo eminentemente relacional, inspira e constitui a relação educativa como relação ética. Finalidade, porque a responsabilidade implica a decisão consciente da aceitação do outro como sujeito de direitos. De facto, se a responsabilidade não fundamentar a educação, esta não chega a emergir porque os processos educativos não serão mais do que meios de despromoção da identidade e da dignidade dos mais frágeis. Se a responsabilidade não fundamentar a educação, os conhecimentos, as técnicas servirão, muito provavelmente, a destruição e a injustiça.

Importa, assim, destacar com especial ênfase a relevância que adquire, em todo este contexto, uma ética da responsabilidade (Joñas, 1994) que se 
faz substituir à segurança da ética da convicção, e que assenta 0 seu estatuto na consciência adquirida de um sujeito que se pretende responsável não so pelo presente, mas também por um futuro a construir.

Por seu lado, a problemática contemporánea dos direitos humanos e consequente emergência de novos direitos, adquire uma nova importância para uma educação que pretendemos se configure, a par e passo, com a prática da liberdade responsável. Para tal, são imprescindíveis quer 0 exercício da indagação filosófica quer uma consciencialização crítica quanto aos direitos humanos.

Mas, a percepção da escola como construtora de cidadãos numa sociedade democrática também não existe fora desta lógica existencial para a qual a filosofia deve contribuir. Considerando as novas exigências da sociedade actual, a reconstrução de sentido(s) e de novas significações para as escolas passa, inevitavelmente, pela construção de um cidadão eticamente responsável, crítico, inteligente, participativo e interveniente numa sociedade que se pretende cada vez mais democrática.

É certo, porém, que tal significaria uma completa transformação da escola num microcosmos democrático como se de uma mini-sociedade se tratasse, à semelhança do que era preconizado por Dewey, onde atitudes de solidariedade, respeito pela opinião dos outros e pelas diferenças, cooperação, diálogo e compreensão seriam vividas e verdadeiramente experienciadas. E... não será esta uma utopia mais próxima de ser realizada?

\section{Conclusão}

A filosofia da educação por ser «filosofia», é reflexão que é realizada pela filosofia de uma forma peculiar, dada a totalidade e a radicalidade que sempre a caracterizaram. 
Tal reflexão sobre a educação caracteriza-se por ser crítica e aberta ao postular contra todo o tipo de dogmatismo educativo, e totalizadora por, ao se situar para além das verdades parciais passíveis de manipulação, procurar articular uma visão integral da realidade educativa.

Nessa caminhada de reflexão filosófica $d a$, na e com a educação, a filosofia da educação revela-se fundamental na sua tentativa de analisar a linguagem educativa e clarificar 0 conceito de educação do ponto de vista filosófico (epistemologia, ontologia e axiologia), adoptando, como lhe é característico, urna perspectiva crítica, sintética e integradora, essencial à compreensão dos mais diversos desafios que a contemporaneidade the vai colocando.

$\mathrm{Na}$ verdade, 0 facto de estarmos «situados num contexto antropológico do saber como é o da contemporaneidade, tudo se decide por isso, mais do que nunca, pelo acesso ao saber e pelo uso que dele se faz» (Carvalho, 2002, 94). Para tal, poderá a filosofia da educação contribuir para 0 necessário desenvolvimento de uma forte exigência cultural que permita, a cada um, uma capacidade de decisão e de opção efectivas, sem se estar sujeito a manipulações sucessivas ao sabor do(s) desejo(s) do poder.

Este forte contributo, que acreditamos que só a filosofia pode ajudar a desenvolver, afigura-se-nos imprescindível e absolutamente necessário num tempo em que praticamente tudo é questionável e, por isso, possível.

Por esta razão, não podemos deixar de considerar crucial 0 papel inalienável que a filosofia da educação possui quanto ao desenvolvimento de uma consciência epistemológica dos professores, bem como quanto ao repensar crítico da sua formação profissional, dada a sua característica fundamental de reflexão aprofundada sobre todo 0 sistema educativo. 
Abbagnano, N. (1976). Historia da Filosofia, I. Lisboa: Ed. Presença.

Auretta, C.; Gonçalves, J. \& Bernardo, L. (2004). Discursos cruzados. Filosofia, Literatura e Educação. Lisboa-. Plátano.

Bernardo, L. (2004). Moscas e caça-moscas: questões de filosofia da educação, in. Auretta, C.; Gonçalves, J. \& Bernardo, L. Discursos cruzados. Filosofia, Literatura e Educação, pp. 81-127. Lisboa: Plátano.

Cabanas, Q. (1988). Teoria de la educación. Concepción antinómica de la educación. Madrid: Dykinson.

Cantillo, E. (1987). Introducción a la filosofia de la educación. Valência: Promolibro.

Carvalho, A. (2001). Filosofia da Educação. Temas e Problemas. Porto: Afrontamento.

Carvalho, A. (1998). A dimensão filosófica dos projectos educativos. Filosofia da Educação. Temas e Problemas, pp. 115-118. Braga: Universidade do Minho.

Fabre, M. (1994). Penser la formation. Paris: PUF.

Fullat, 0. \& Sarramona, J. (1982). Questiones de Educación. Barcelona: CEAC.

Heitger, M. (1993). Sobre la necesidad de una fundamentación filosófica de la pedagogía. Revista española de pedagogia. 51, (194), pp. 89-99.

Jonas, H. (1994). Técnica, Medicina e Ética. Lisboa: Ed. Passagens.

Lyotard, ].- F. (1989). A condiçãopós-moderna. Lisboa: Gradiva.

Medeiros, E. (2002). Educação filosófica e experiência reflexiva: elementos para uma interacçã̃o entre utopia e pragmatismo. Actas II Colóquio de Filosofia da Educação. Utopia e Pragmatismo em Educação: desafios eperspectivas, pp. 125-150. Ponta Delgada: Univer sidade dos Açores.

Nassif, R. (1985). Teoria de la educación. Madrid: Cincel.

Ozmon, H. \& Craver, S. (1976). Philosophical foundations of education. Ohio: Columbus.

Pedro, A. (2002). Educação em Valores em Portugal. Estratégias epercursos. Lisboa: Ministério da Ciência e Tecnologia/Fundação Calouste Gulbenkian.

Kneller, G. (1979). Introdução à filosofia da Educação. Rio de Janeiro: Zahar Ed.

Reboul, 0. (1989). La philosophie de l'éducation. Paris: PUF.

Saez, J. (1985). Filosofia de la educación, in. Ferrández, A. \& Sarramona, J. La educación. Constantes y problemática actual. Barcelona: CEAC. 